\title{
Ejector fan installations used in mines of Russia
}

\author{
N I Alymenko \\ Laboratory of Geo-technological processes and mining gas- \\ dynamics \\ Mining Institute of Ural Branch of Russian Academy of \\ Sciences (MI UB RAS) \\ Perm, Russia \\ E-mail: nik.alymenko@yandex.ru
}

\author{
A A Kamenskikh \\ Laboratory of Geo-technological processes and mining gas- \\ dynamics \\ Mining Institute of Ural Branch of Russian Academy of \\ Sciences (MI UB RAS) \\ Perm, Russia \\ E-mail: Timr2418@mail.ru
}

\author{
A V Nikolaev \\ Laboratory of Mining Electromechanics \\ Perm National Research Polytechnic University (PNRPU) \\ Perm, Russia \\ E-mail: nikolaev0811@mail.ru
}

A I Petrov

Laboratory of Geo-technological processes and mining gasdynamics

Mining Institute of Ural Branch of Russian Academy of Sciences (MI UB RAS)

Perm, Russia

E-mail: alex231287@yandex.ru

\begin{abstract}
In the article, the options of mines aeration by means of ejector fan installation are examined, as well as the principle of this installation functioning and its potential are shown. Basing on the investigations conducted and the functioning results received, the possibility of application of the ejector fan installation as the main and auxiliary fan installation is shown. The application of the ejector fan installation as the main fan installation for aeration of the mines of the fields opened with adits or shafts of small extent on the northeast of Russia is proved. The option of using the ejector fan installation in the pit mouth as well as in underground stopings of the mine ventilating network is considered.
\end{abstract}

Keywords - mine ventilating; main fan installations; ejector fan installations; underground mobile fan installation; aerodynamic drag

\section{INTRODUCTION}

The North is the unique part of the Earth. When looking at the map of Russia, it becomes obvious that the big part of Russian area is related to the North. Let us focus on the northeast of Russia, particularly, on Khabarovsk Krai, Magadan region and Chukotka.

The main fan installations (MFI) are the key link supplying the mine with a necessary amount of the air. The development of fans construction was mainly oriented to the aeration of coal mines. The centrifugal fans, capable to develop high static pressures and productivity changing over a wide range, were created. Such fans of the main airing satisfied the ventilating needs of the deep mines having considerable aerodynamic resistance of ventilating networks [3]. For less deep mines with the smaller aerodynamic resistance, the axial fans of several standard sizes are used [2]. Such approach is justified when the mine field is opened with vertical or inclined shafts which create the main part of ventilating network depression. From air giving to ventilating shafts, the mine tunnels have, as a rule, the insignificant aerodynamic resistance, for which from 5 to $15-20 \%$ of a depression of the whole ventilating network are spent [1].

In practice, the fans-ejectors are sometimes used for aeration of mines [6]. However, fans-ejectors cannot unambiguously solve the problem of necessary air distribution through the sections of the ventilating network as they have no constant aerodynamic characteristics [5].

The ejector fan installations (EFI) have advantages of the fan-ejector, but have constant aerodynamic characteristics during the work in the ventilating network with variable resistance. EFI has in its structure the merging chamber for ejecting and ejected streams of air which is established in a mine tunnel together with the fan (fig. 1-2). To exclude the circulation of an air stream in a mine tunnel, the separation wall is established between the merging chamber and the mine tunnel walls. Thus, there is an EFI aerodynamic system with constant aerodynamic characteristics working in the ventilating network with variable resistance [6].

Underground mine tunnels must be aired by means of continuously operating MFI. There are several requirements for MFI, regarding its structure, location, work control devices, air supply and pressure, the reversal of a ventilating stream, a way of aeration [7-9]. 


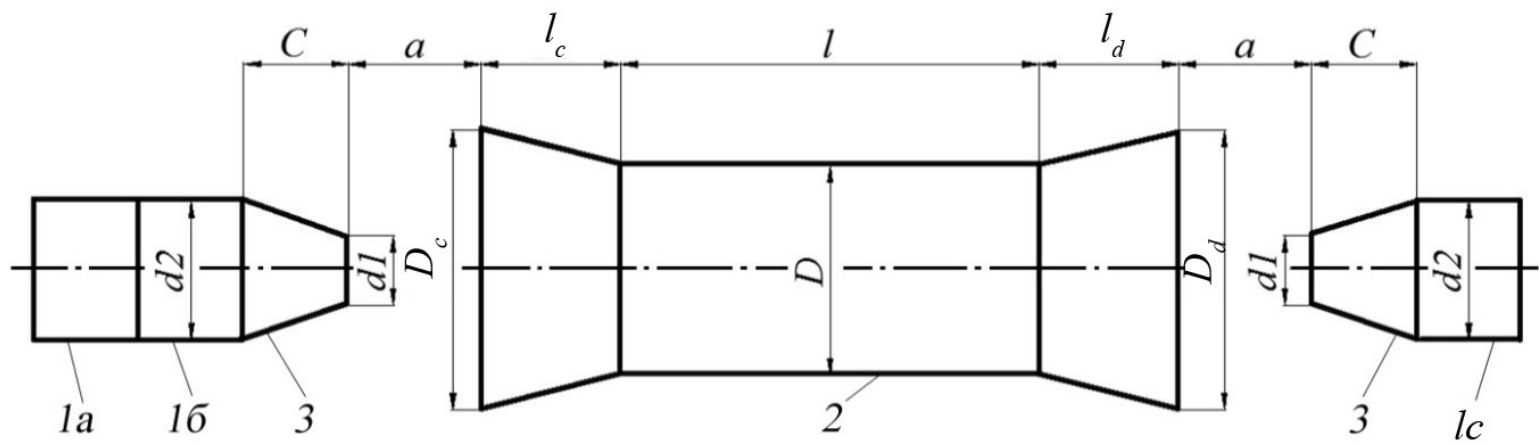

Fig. 1. Schematic aerodynamic diagram of EFI (UMFI): 1 - fan (a - working, $\mathrm{b}$ - reserve, $\mathrm{c}$ - reversal); 2 - merging chamber; 3 - nozzle; D, $D_{c}, D_{d}$ - diameter of direct-flow part of merging chamber, confuser, diffuser; $l, l_{c}, l_{d}$ - length of direct-flow part of merging chamber, confuser, diffuser; $d_{l}, d_{2}-$ nozzle diameters; $a$ - distance from nozzle to confuser (diffuser)

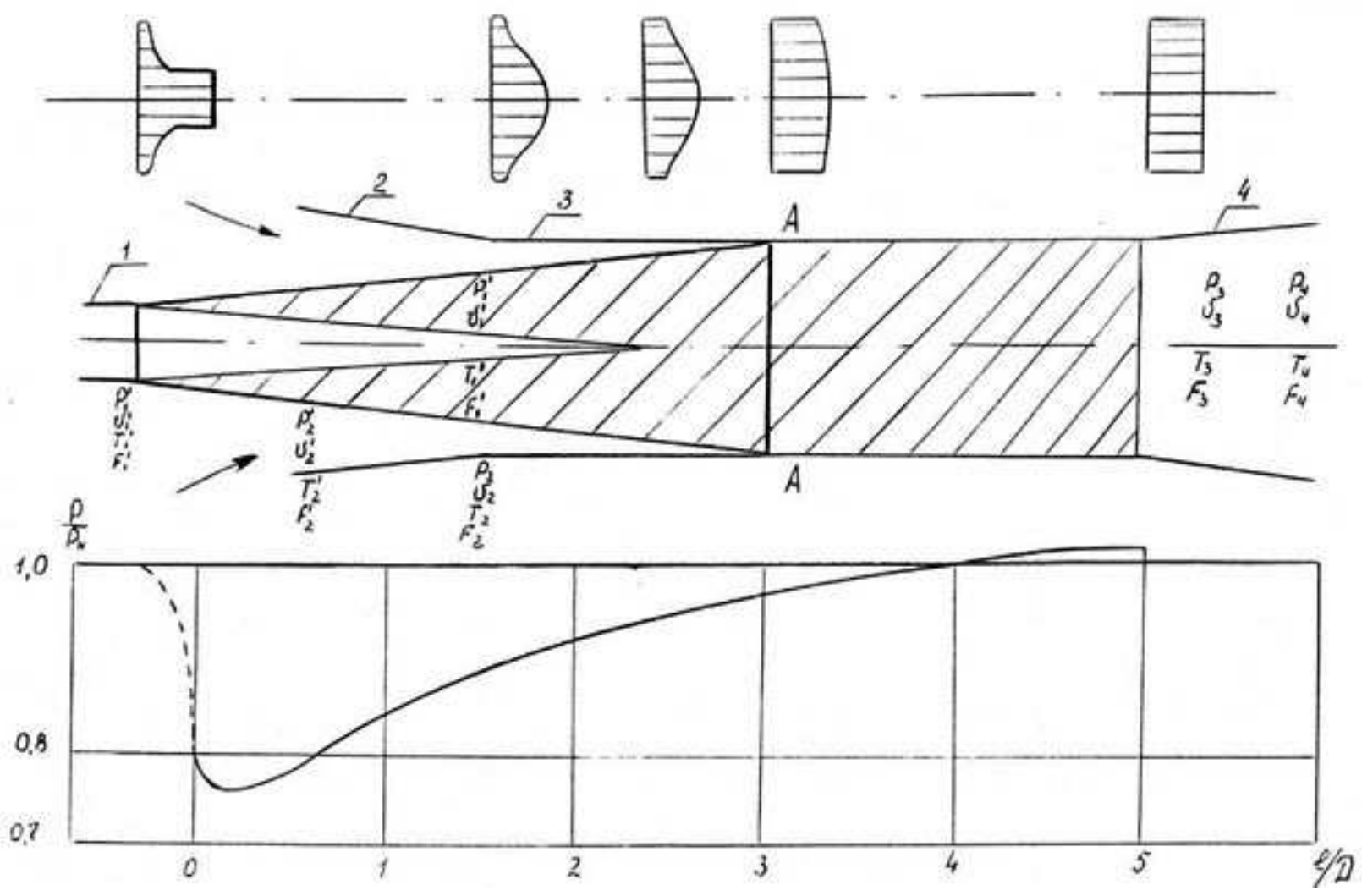

Fig. 2. Scheme of flow and variation of velocity field and static pressure along length of displacement chamber: 1 outlet nozzle; 2 - intlet nozzle; 3 - mixing chamber; 4 - diffuser. 


\section{RESULTS AND DISCUSSION}

To choose MFI (including the type of its construction: axial or centrifugal), it is necessary to base on the required pressure to overcome the ventilating network resistance and the design capacity. The field of industrial fans application is limited by aerodynamic characteristics and the 0,6 efficiency factor. There are no zones of efficient performance within 01000 Pas on the work schedules of MFI [2].

However, now there is a significant number of functioning mountain mines with low production capacity with the representative section of the ventilating system, being considerably more than $2 \mathrm{~m}^{2}$. Such mines, as a rule, have the adit opening, do not have the airgiving and ventilating shafts, and MFIs develop low pressure which leads to work in the field of low efficiency factor values. The life cycle of such mountain enterprises is usually less than MFI life. Its shortage is caused by considerable expenses (especially in the conditions of the northeast) as MFI of such mines works in low-pressure zones (sometimes the pressure is much lower than 1000 Pas) providing necessary supply of fresh air in mine tunnels.
From [6] it follows that the underground mobile fan installation (UMFI) or EFI (the difference is in the name, but it is the same thing) is intended for air redistribution in the sections of ventilating networks of mines, tunnels, subways with the representative section over $2 \mathrm{~m}^{2}$. The constant aerodynamic characteristics are specific for these installations. Such installations can be established in mine tunnels, do not demand construction of the building on the surface, ventilating channels. The reversion of a ventilating stream is realized by installing the reversible fan at $180^{\circ}$ to the working fun (from the side of the merging chamber diffuser).

Based on the results of industrial EFI (fig. 3), tests on such mines as SKRU-2 of "Silvinit" JSC, "Mnogovershinnyi", "Dukat", "Karalveem", and the model tests executed in the State Research Center "CADI" (central aerohydrodynamic institute) of N. E. Zhukovsky [4], there were received ratios for determination of the EFI optimum parameters with different fans (fig. 3-5):

$$
D / d_{2}=1,5 ; d_{l} / d_{2}=2,0 ; D / d_{l}=3,0 ; l_{c} l_{d}=1,31 D ;\left(a+l_{C}\right) / D
$$

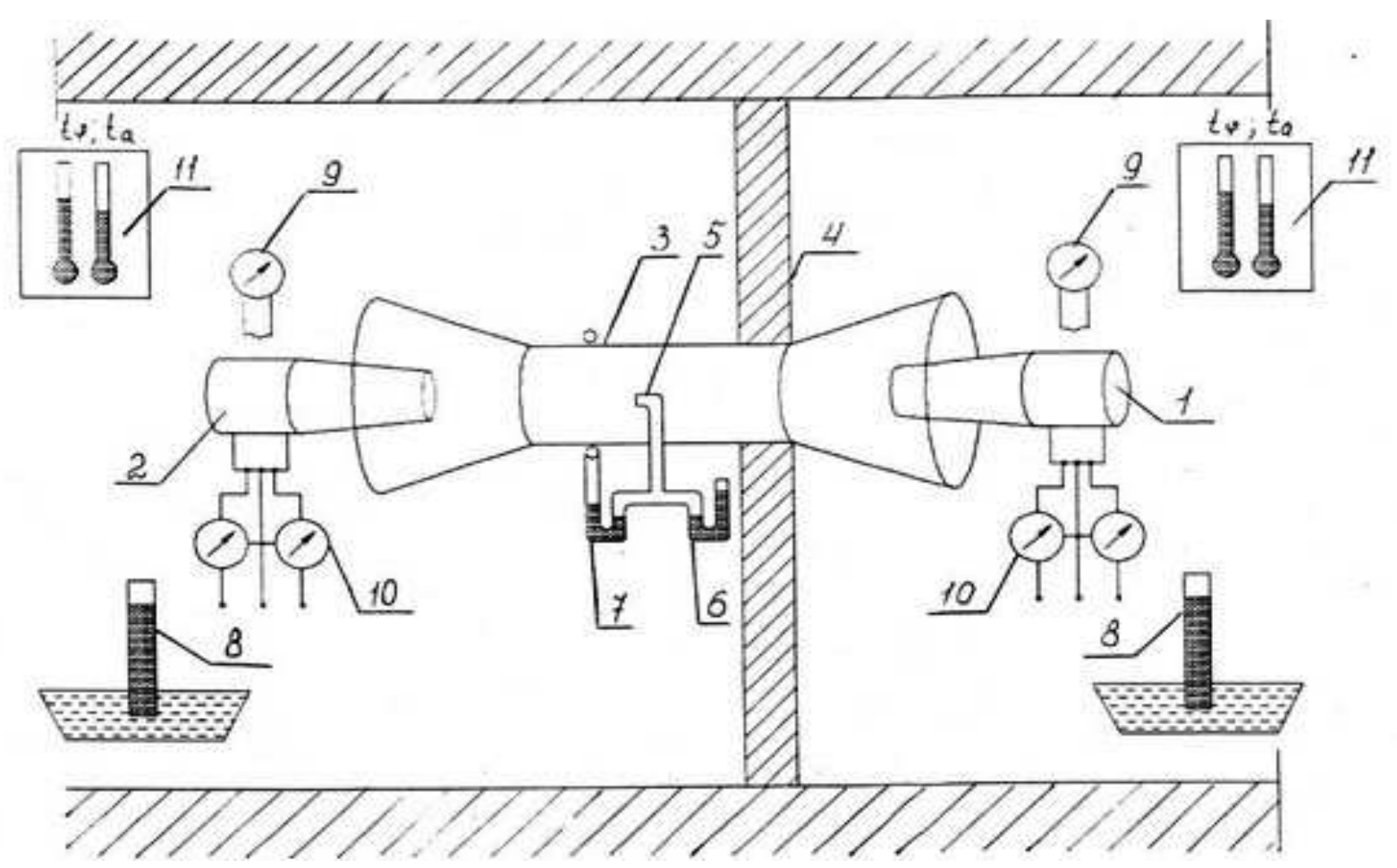

Fig. 3. Scheme for aerodynamic testing: 1 - fan; 2 - reversible fan; 3 - venturi; 4 - jumper; 5 - combined pressure receptacle; 6 - differential pressure meter; 7 - differential pressure gauge; 8 - barometer; 9 - Speed meter; 10 - devices for measuring power; 11 - psychrometer. 


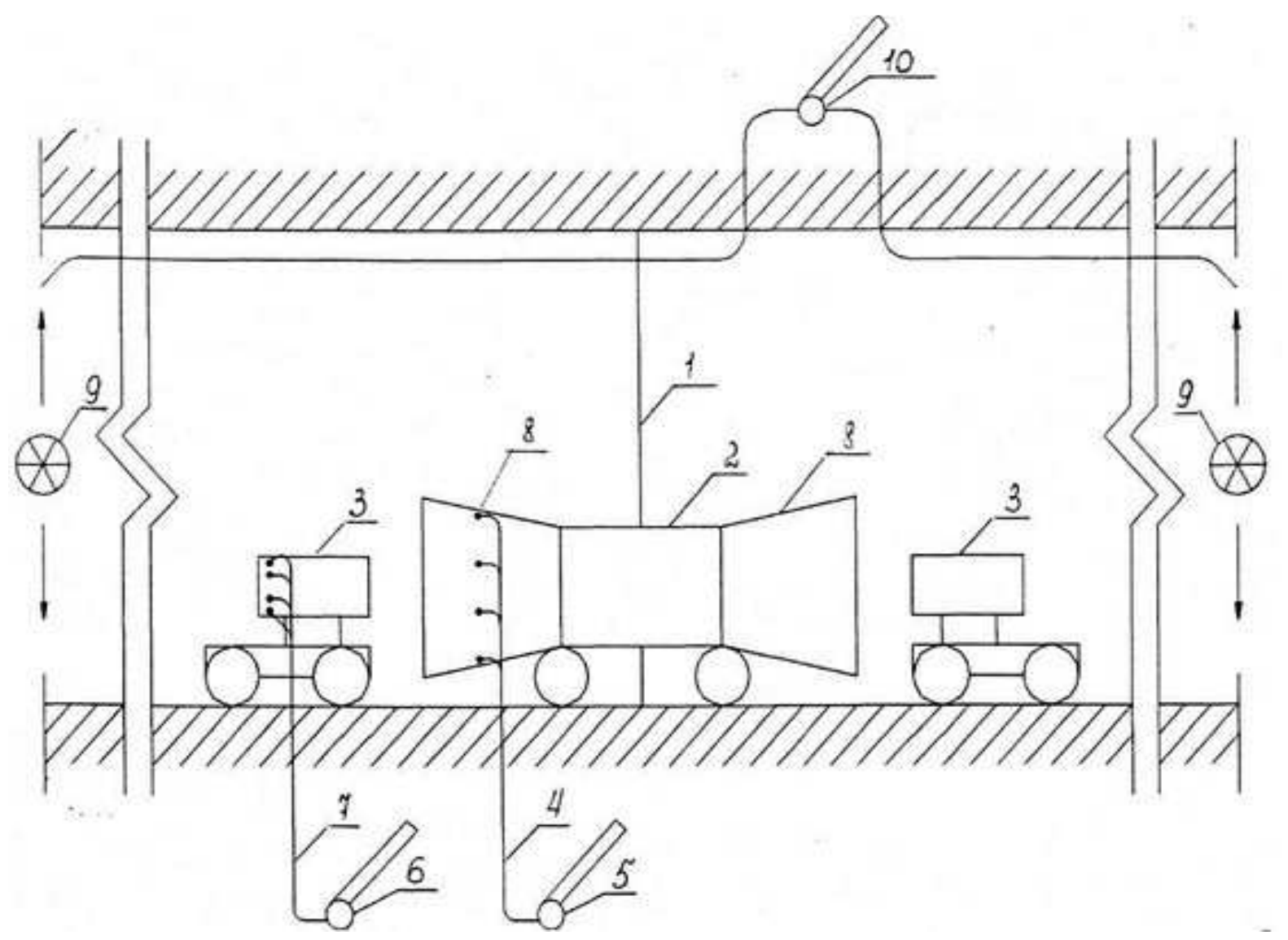

Fig.4. Scheme of arrangement of equipment and measuring instruments during testing: 1 - jumper; 2 - venturi; 3 - fan VME-6; 4, 7- measuring tubes; 5, 6, 10 - micromanometers; 8 - diffuser (confusor); 9 - anemometer; I-I and 2-2 - flow measurement section.

The parameters of the EFI functioning are controlled by the equipment, similar to the that installed on MFI, or by other control-measuring equipment, allowed for these purposes in accordance with the established procedure.

The calculations of ventilating networks do not always confirm that the MFI installation on the surface is reasonable. In domestic and foreign practice, the underground MFI installation occurs now more often. As the calculations and the operating experience show, it is a more economic and reliable aeration solution for the underground mine enterprises from different viewpoints. EFI working as MFI can be placed both on the Earth's surface and in mine tunnels [10, 11]. When EFI is placed underground, the smaller volume of construction works is required and it is possible to put EFI in the optimum place from the viewpoint of air distribution in the ventilating network. For mines with small air expenses $\left(10-120 \mathrm{~m}^{3} / \mathrm{s}\right)$, it is possible to make EFI mobile or easily demountable on mobile units that will allow one to easily reinstall it when closing the mine

(fig. 4). 


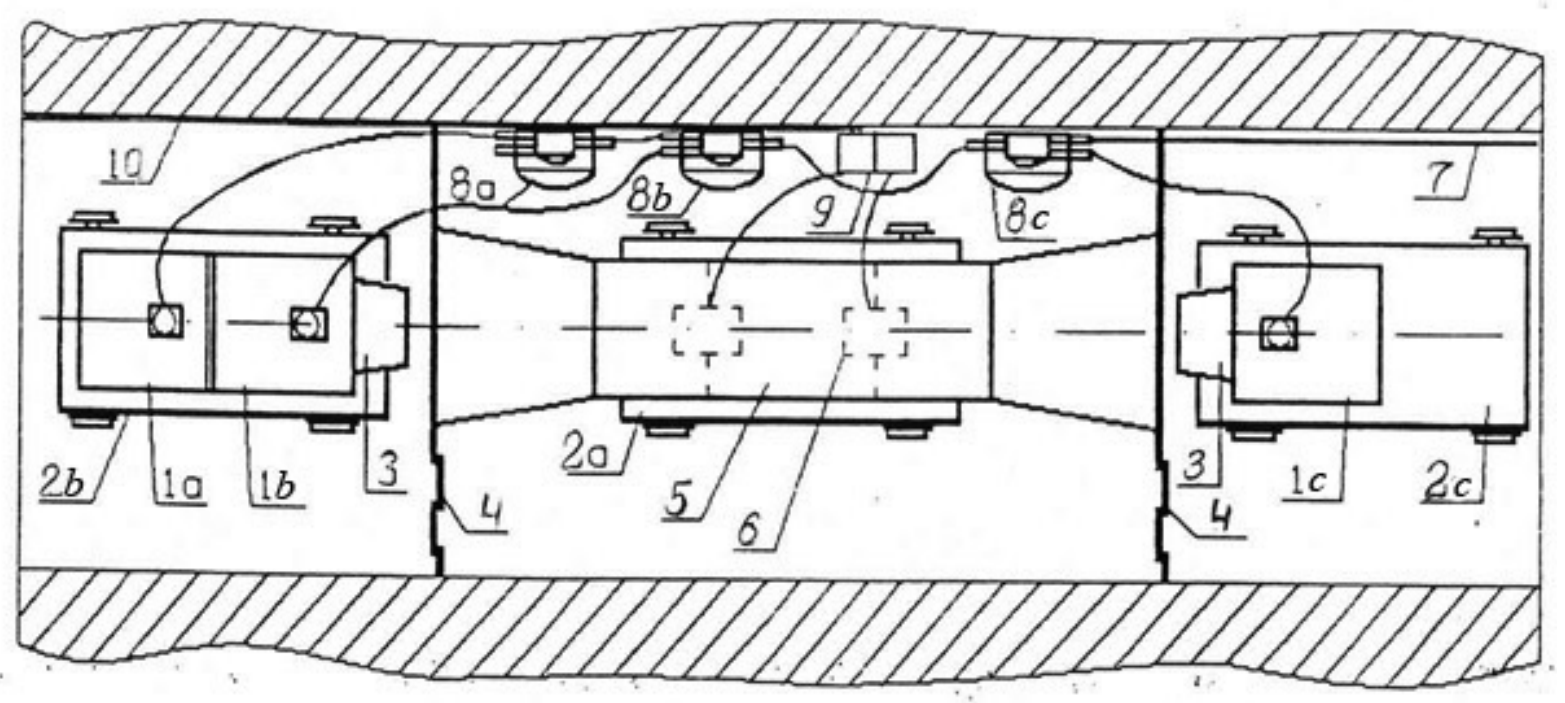

Fig. 5. Layout of fan installation UMFI in mine (view from above): 1 - fan (a - working fan, b- standby fan, c - reversible fan); 2 - frame of trolley VG-4 (a - frame of a car for Venturi, c, b- frame of a trolley for fans); 3 - nozzle; 4 - jumper; 5 - Venturi;

6 - instrument sensor APTV; 7 - supply cable; 8 - fan starter ( $a, b$ - fan contactor direct work, $\mathrm{c}$ - reversing fan motor starter), 9 - instrument control panel APTV; 10 - conclusion to the dispatcher of the mine.

In theory, any standard sizes of fans, both axial and centrifugal, can be used for EFI. In EFI, serially released fans of local aeration are used (fig.6).

\section{EJECTOR FAN INSTALLATIONS}

"Mnogoveshinnyi" mine is situated in the north of Khabarovsk Krai. The aeration of separate chambers and the mine by means of underground mobile installations of ejector type was tested and put into operation. Their work in the parallel mode, when placed in different mine tunnels for airing of "Promezhutochnoe" and "Yuzhnoe" chambers, was investigated. The alternative for EFI was MFI with V0D-16 fan. The total productivity of two EFIs made up $58,7 \mathrm{~m}^{3} / \mathrm{s}$, with a static pressure of 130 Pas. In 2003, with the increase of mining works localization, mine capacity of EFI with VME-6 fan was replaced with EFI with the VME-8 fan and its location was changed.

The use of EFI, as MFI, has been realized in 2002 on the "Dukat" mine of CJSC "Serebro Magadana". EFI with the VME-12AU5 fan has been designed, approved in accordance with the established procedure and put into operation. It worked as MFI and supplied the mine with $65,0-157,4 \mathrm{~m}^{3} / \mathrm{s}$ of air with $51,0-150,0$ Pas pressure. The productivity setting is carried out by changing fan driving wheels at $+15^{\circ},+25^{\circ}$, $+35^{\circ}$ installation angles of the blades and by changing the distance between the exit nozzle of the fan and the merging chamber entrance. The reversal of a ventilating stream was carried out by the VME12 AU5 fan located at 180 degrees to the working fan. The work parameters at reversion are almost equal to the normal work parameters. 


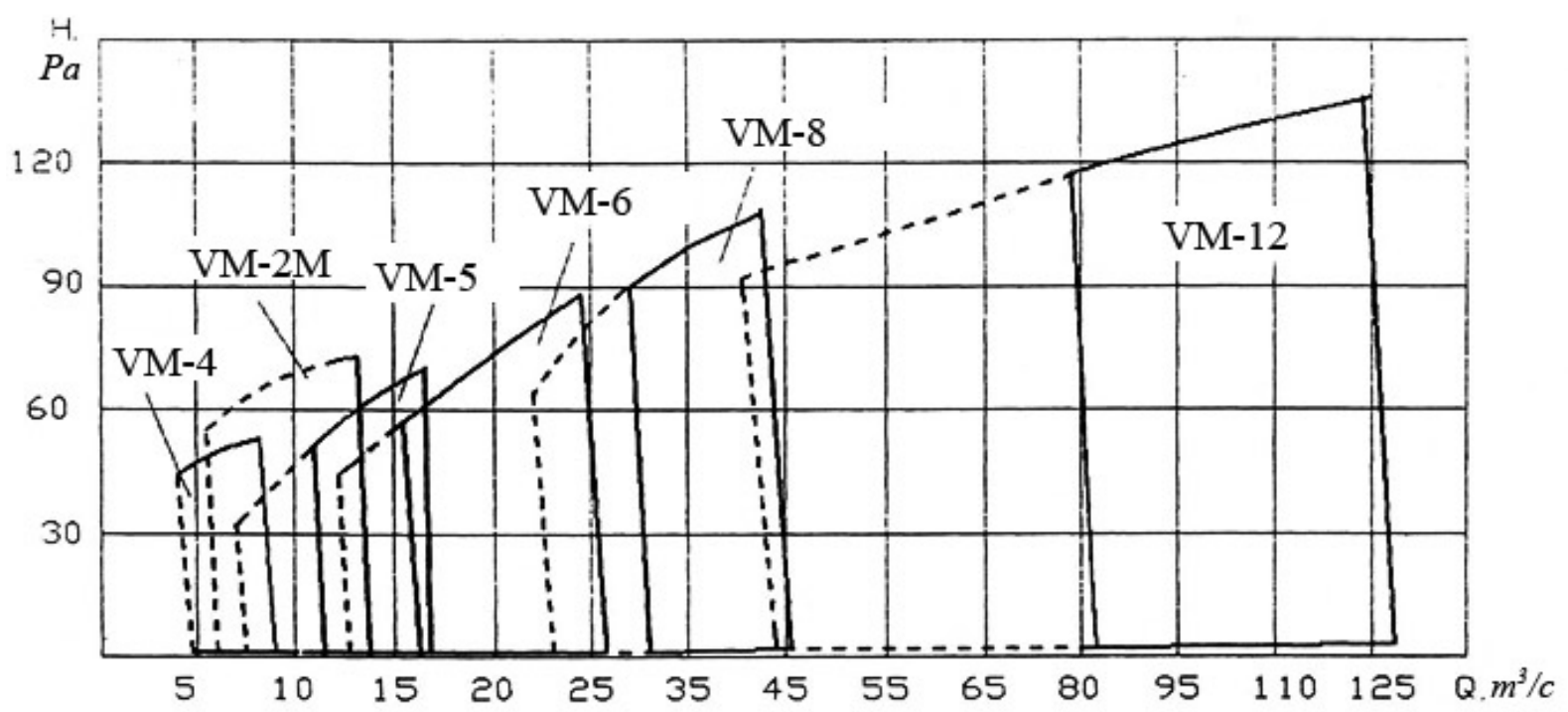

Fig. 6. Aerodynamic characteristics of UMFI.

To confirm the solution relevance, MFI with the VME12AU5 fan was tested in the "Ducat" mine in different operating modes within more than 2 weeks. During the tests, the supplying tunnel to MFI has been blocked by $90 \%$ by the separation wall. On this fan, the driving wheel with the +350 installation angle of blades has been installed (the maximum productivity), and the fan has been installed on a frame for coincidence with the fan axis and the merging chamber.

Permanently frozen ground partially thawed, and the frame of the fan stood in a pool, which surface was at a distance of $1157 \mathrm{~mm}$ from the fan. The fan worked, measurements were made; at this moment, the water column has risen from a pool and via the fan, the fan nozzle and the merging chamber has been thrown out in the tunnel. The normal work of MFI was confirmed and the installation has been put into operation. Originally, EFI was placed in the mine at distance of $530 \mathrm{~m}$ from the mouth of the intake at the point of $+980 \mathrm{~m}$. And in the second half of 2003, in connection with the approach of the mining operations close to EFI, it was moved to the new place by $15 \mathrm{~m}$ away from the mouth of adit No. 9. When carrying out the tests of EFI, it was shown that the mine can be aired both by the forcing and exhaust methods. Each of aeration ways has the advantages during different periods of year, depending on the influence of seasonal natural draft. Subsequently, EFI located in the mouth of adit No. 64 was put into operation in the "Ducat" mine.

\section{CONCLUSION}

Thus, it is possible to conclude about a possibility of application of EFI as MFI. The design productivity is reached by the choice of a fan size used in EFI. Owing to the design of aerodynamic features of the considered EFI and simplicity of merging chambers production, it is possible to put EFI at an optimum point of the ventilating network, and to move to the new place when required. It is very important during construction and commissioning of new mines.

The analysis of ventilating systems' work of north-east mines of Russia (The Magadan region, Chukotka and Khabarovsk Krai) implies that by means of EFI, many mines can be aired, or EFI can be used for air redistribution in the sections of the ventilating network.

For the particular mine, the aeration issue by means of EFI is resolved by means of the project with coordination of design decisions in accordance with the established procedure.

EFI design was constantly improved; it is confirmed by 11 patents of the Russian Federation.

\section{REFERENCES}

[1] N.I. Alymenko, V.V. Minin, Fan installations and its application, Yekaterinburg: UrD RAS, 1999, p. 223.

[2] B.F. Bratchenko, Fixed mines installations, M.: Nedra, 1977, p. 440.

[3] N.I. Alymenko, A.A. Kamenskikh, A.V. Nikolaev, A.I. Petrov, "Choosing the main fan installation. Urgent problems of increase in efficiency and safety of operation of the mining and oil-field equipment," Proc. Of conference Mountain electromecanics, pp. 190-199, oktober 2015 [II international scientific and practical conference Mountain electromecanics, 2015].

[4] I.I. Medvedev, A.E. Krasnoshtein, Aerology of potash mines, Sverdlovsk: UrD AS USSR, 1990, p. 250.

[5] K. Z. Ushakov, Mines ventilation, M.: Nedra, 1988, p. 440.

[6] N.I. Alymenko, A. S. Ginevskii, State Research Center CADI, scientific and technical report. Experimental study of model of fan ejector installation for mines aeration. Moscow, 1992, p. 26.

[7] Jianwei Cheng, Yan Wu, Haiming Xu, Jin Liu, Yekang Yang, Huangjun Deng, Yi Wang, "Comprehensive and integrated mine ventilation consultation model," Tunneling and underground space technology, Vol. 45, 2015, pp. 166-180. DOI: 10.1016/j.tust.2014.09.004.

[8] W. J. Kempson, Webber- R. C. W. Youngman, J. P. Meyer, "Optimising shaft pressure losses through computational fluid dynamic modelling," APPLIED THERMAL ENGINEERING, Vol. 
90, 2015, $\quad$ pp.. $\quad 1098-1108 . \quad$ DOI: 10.1016/j.applthermalend.2015.04.058.

[9] Zhu Pei-gen, Tong Xiao-na, Chen Lei, Wang Chun-wang, Song Hua, Li Xiao-yun, "Influence of opening area ratio on natural ventilation in city tunnel under block transportation," SUSTAINABLE CITIES AND SOCIETY, Vol. 19, 2015, pp. 144-150. DOI: 10.1016/j.scs.2015.07.015.

[10] E. L. Grishin, N. A. Trushkova, "Choice of parameters of operation of auxiliary fans and places of their arrangement in the mine to provide fresh air to difficult breathing zone," Mining informationanalytical bulletin, Vol. 8, 2013, pp. 304-307.

[11] M. Y. Liskova, I. S. Naumov, "Need to study the work of ejected plants in mines," Reports of the XXIII international scientific symposium. Miner`s week, 2015, pp. 157-161. 